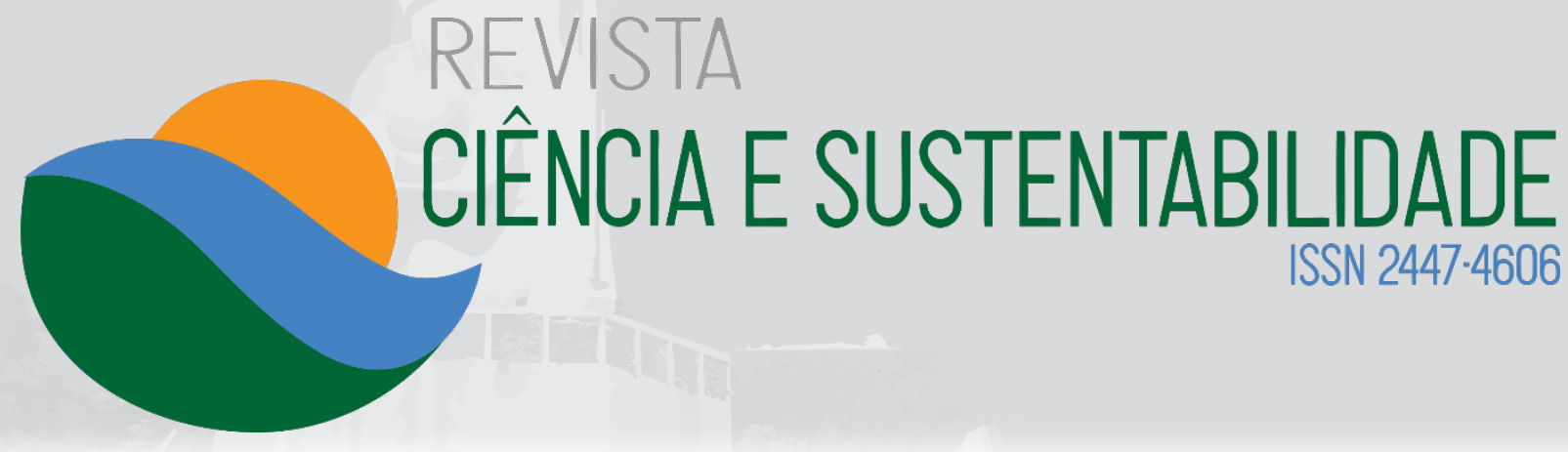

\title{
Análise dos sistemas de monitoramento e alerta hidroclimáticos implementados no município de Altamira/Pa
}

\section{Analysis of hydroclimatic monitoring and warning systems implemented in the} municipality of Altamira/Pa

\begin{abstract}
Nelson Paulo Martins de Queiróz Júnior

Universidade Federal do Pará (UFPA) Engenheiro Sanitarista e Ambiental

(Faculdade de Engenharia Sanitária e Ambiental)

nelsondequeirozjr@gmail.com
\end{abstract}

\begin{abstract}
Resumo
As inundações em áreas urbanas afetam significativamente o cotidiano da população, causando uma série de danos e perdas irreparáveis. O município de Altamira, localizado no sudoeste do Pará, possui um extenso histórico de desastres hidrológicos registrados. Neste contexto, o presente trabalho tem como objetivo analisar os sistemas de monitoramento e alerta hidroclimáticos implementados no município em questão, possibilitando identificar os problemas enfrentados na operação destes sistemas e pontuar as fragilidades existentes. Para isso, foi realizada pesquisa bibliográfica e documental, para levantar informações que fundamentassem a pesquisa, e por fim, foram realizadas entrevistas semiestruturadas com o intuito de analisar as diferentes percepções dos agentes envolvidos. De acordo com os resultados obtidos, além das dificuldades existentes no monitoramento e na obtenção de recursos para os sistemas, também foi mencionada a falta de interesse do Poder Público em adotar medidas de prevenção de danos e capacitação da população para enfrentar situações de risco iminente. Recomenda-se que o poder público busque atuar de forma conjunta, tanto com os órgãos públicos responsáveis pelos sistemas de monitoramento e alerta quanto com os agentes de defesa civil, além de estabelecer contato constante com a população.
\end{abstract}




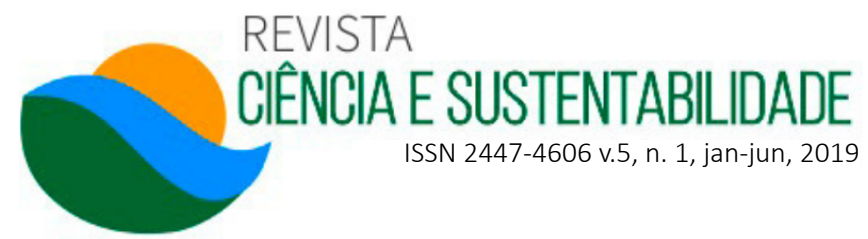

Palavras-chave: Inundação. Enxurrada. Desastre.

\begin{abstract}
Flooding in urban areas significantly affects the daily lives of the population, causing a number of irreparable damages and losses. The municipality of Altamira, located in the southwest of Pará, has an extensive history of recorded hydrological disasters. In this context, the present work aims to analyze the hydro climatic monitoring and warning systems implemented in the municipality in question, making it possible to identify the problems faced in the operation of these systems and to point out the existing fragilities. For this, a bibliographical and documentary research was carried out to gather information that would support the research, and finally, semi-structured interviews were conducted with the purpose of analyzing the different perceptions of the agents involved. According to the results obtained, in addition to the difficulties in monitoring and obtaining resources for the systems, it was also mentioned the lack of interest of the public power to adopt measures to prevent damage and capacity of the population to face situations of imminent risk. It is recommended that the Public Authorities seek to act jointly with both public agencies responsible for monitoring and alert systems and with civil defense agents, in addition to establishing constant contact with the population.
\end{abstract}

Keywords: Flood. Flash flood. Disaster. 


\section{INTRODUÇÃO}

O crescimento acelerado e desordenado das cidades, aliado às ausências de planejamento urbano, técnicas de construção adequadas e de educação básica, sanitária e ambiental, têm sido agentes potencializadores de situações de risco, que se efetivam em desastres por ocasião de eventos naturais, nos grandes e pequenos núcleos urbanos (CPRM, 2013).

Segundo o Ministério do Planejamento e Orçamento (1998), em seu Glossário de Defesa Civil, desastre seria o resultado de eventos adversos, naturais ou antrópicos, sobre um ecossistema (vulnerável), causando danos humanos, materiais e/ou ambientais e consequentes prejuízos econômicos e sociais. Em relação às perdas, as inundações são responsáveis por cerca de $50 \%$ do total de prejuízos ocasionados por desastres (KRON, 2003).

No ano de 2013, em estudo realizado por Fava etal (2013), os custos econômicos totais das inundações em nosso país, diretos e indiretos, chegam até $3 \%$ do PIB nacional e os danos comprometem o equivalente a $11 \%$ de fontes de arrecadação.

Segundo Soares et al (2005), as inundações em áreas urbanas provocam impactos nas atividades comerciais, nos serviços, no transporte e no cotidiano da população atingida. Os prejuízos ocasionados pelas inundações se dão em função de dois fatores: a magnitude do evento e a vulnerabilidade da área (SAMUELS, 2000). Ou seja, o ideal seria adotar medidas de controle que atuem tanto na previsão do evento quanto na redução da vulnerabilidade da área exposta, e assim reduzir os prejuízos associados a estes desastres hidrológicos.

Em relação à previsão de riscos hidrológicos (alagamentos, inundações, enxurradas), uma das formas de atuação é a implementação de sistemas de previsão e alerta, que possuem a finalidade de se antecipar à ocorrência da inundação, avisando a população e tomando as medidas necessárias para reduzir os prejuízos resultantes (TUCCI, 2005).

Oliveira et al (2015) realizaram um levantamento histórico das inundações no município em questão, onde identificaram dois tipos de fenômenos de subida das águas nas áreas urbanas: um lento e gradual de certa previsibilidade denominado de inundação; e um processo rápido e catastrófico e com alto poder de destruição, que é 
conhecido como enxurrada1.

Segundo os autores supracitados, ambos os casos estão associados a variáveis naturais, que são o volume precipitado, os eventos de grande escala como La Niña e a própria dinâmica fluvial. Entretanto, também há a interação de diversas variáveis de origem antrópica, como a ocupação das planícies de inundação, alteração na morfologia da bacia e a construção de barragens clandestinas nas cabeceiras (OLIVEIRA et al, 2015).

As inundações recorrentes no município de Altamira causam diversos impactos nas comunidades atingidas. Este trabalho surge com a proposta de analisar os sistemas de monitoramento hidroclimáticos para previsão e alerta implementados em Altamira, além de identificar os problemas enfrentados na operação destes sistemas através das percepções dos agentes envolvidos.

Neste contexto, abordar esta temática é de extrema relevância para a comunidade acadêmica e a sociedade em geral, pois ainda que o município de Altamira possua um extenso histórico de inundações e perdas irreparáveis, pouco se discute sobre o assunto.

\section{METODOLOGIA}

O município de Altamira está localizado no sudoeste do Estado do Pará, distante $512 \mathrm{~km}$ em linha reta, da capital do Estado, Belém, ou $720 \mathrm{Km}$ por via rodoviária na rota de Tucuruí (ALTAMIRA, 2010).

O município de Altamira possuía uma população de 99.075 habitantes, de acordo com o último Censo Demográfico do IBGE (2010), e população estimada de 113.195 habitantes para o ano de 2018. Possui uma área de $159.533,328 \mathrm{~km}^{2}$. Na Figura 1, observa-se a localização do município no Estado do Pará.

\footnotetext{
1 "Escoamento superficial de alta velocidade e energia, provocado por chuvas intensas e concentradas, normalmente em pequenas bacias de relevo acidentado. Caracterizada pela elevação súbita das vazões de determinada drenagem e transbordamento brusco da calha fluvial. Apresenta grande poder destrutivo (COBRADE, 2012)."
} 
Figura 1 - Localização do município de Altamira
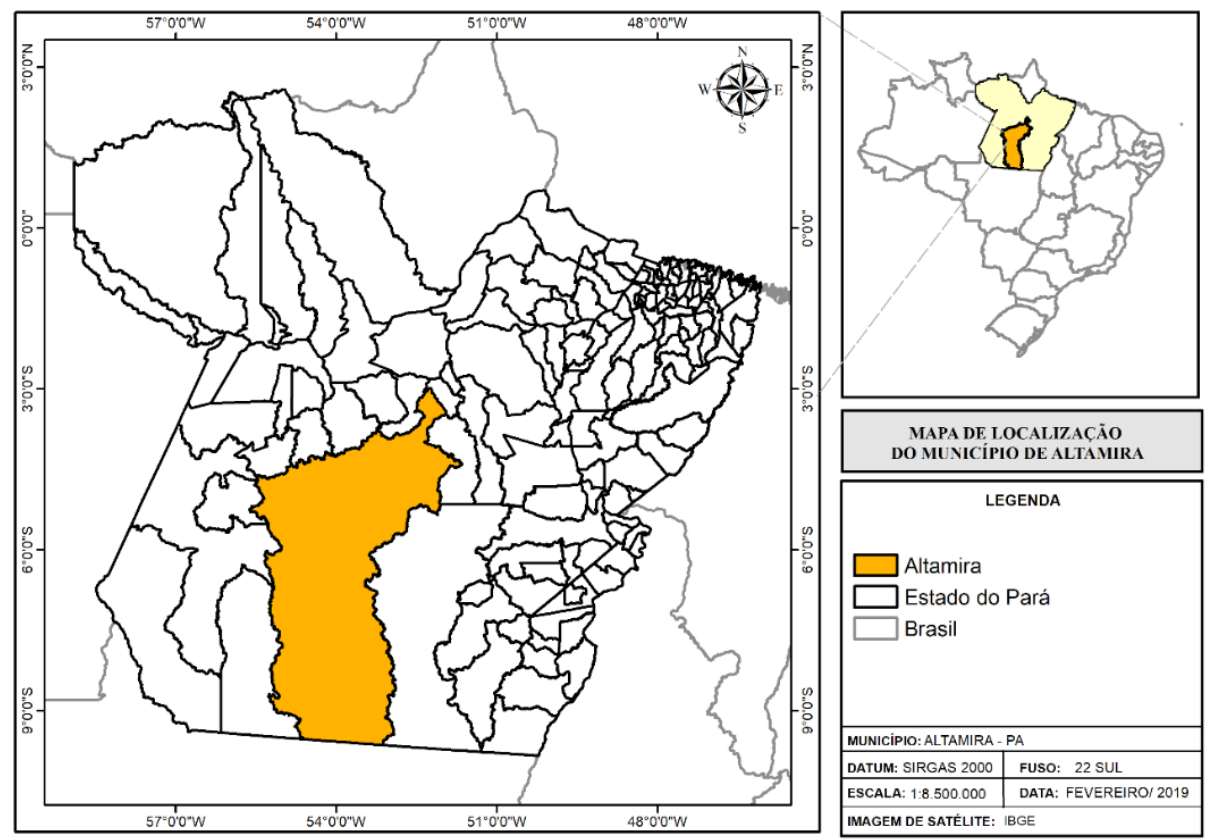

Fonte: Autor (2019).

O presente estudo foi divido em 3 etapas metodológicas, que buscaram atender aos objetivos levantados na pesquisa. Na primeira etapa, foram consultados dados de diversos órgãos públicos, como o Instituto Brasileiro de Geografia e Estatística (IBGE), Instituto Nacional de Meteorologia (INMET), Ministério da Integração Nacional (MI), entre outros, onde foram obtidos dados referentes a população, área do município, índices pluviométricos e outras informações pertinentes a pesquisa.

Também foi consultada a base de dados do Sistema Integrado de Informações sobre Desastres (S2ID), do Ministério da Integração Nacional, onde constam os decretos expedidos pela Prefeitura e pelo Governo do Estado, bem como os documentos expedidos pela Defesa Civil Municipal acerca das inundações em Altamira, afim de identificar as medidas adotadas pelo município mediante desastres hidrológicos iminentes na região.

$\mathrm{Na}$ etapa seguinte, foram utilizadas informações obtidas nos endereços eletrônicos oficiais dos órgãos públicos responsáveis pela operação dos sistemas de monitoramento e alerta hidroclimáticos implementados no município de Altamira: o sistema operado pela UFPA/SUDAM e o sistema operado pela CPRM. Algumas 
informações complementares também foram obtidas nas entrevistas semiestruturadas realizadas com os representantes dos sistemas em questão.

$\mathrm{Na}$ terceira e última etapa foram realizadas entrevistas semiestruturadas com agentes envolvidos nos sistemas de monitoramento e alerta hidrológicos implementados no município. As entrevistas foram realizadas nas sedes da SUDAM, CPRM e Defesa Civil Estadual. Esta etapa buscou avaliar as dificuldades existentes no monitoramento e emissão de alertas em Altamira, verificar quais as medidas adotadas no município para prevenção e mitigação de desastres hidrológicos e analisar as percepções dos agentes envolvidos.

\section{RESULTADOS E DISCUSSÕES}

Nesta seção serão apresentados e discutidos os resultados obtidos durante o levantamento de informações acerca dos sistemas de monitoramento e alerta hidrológicos implementados em Altamira. Por questões éticas, os nomes de todos os participantes foram suprimidos.

\section{Sistema de monitoramento e alerta hidroclimático - UFPA/SUDAM}

Através do Termo de Cooperação Técnica n03/2012, firmado entre a Superintendência de Desenvolvimento da Amazônia (SUDAM) e a Universidade Federal do Pará (UFPA), foi criado o Centro de Monitoramento Hidroclimático da Amazônia, desenvolvendo atividades de monitoramento das principais bacias e subbacias hidrográficas da Amazônia (Tocantins, Xingu, Tapajós, Médio Amazonas e Rio Branco) e realizando a previsão de alertas, com a elaboração de boletins hidroclimáticos e focos de calor, abrangendo os principais municípios da região amazônica.

Em relação ao índice pluviométrico do município, na Figura 2, observa-se o comportamento sazonal de precipitação. Assim como em grande parte da região Norte, o regime pluviométrico do município em questão é definido entre os meses de dezembro a maio, sendo que as chuvas no mês de março normalmente superam volume acumulado de $350,0 \mathrm{~mm}$, com média histórica de $378,0 \mathrm{~mm}$. A partir do mês de maio, tem-se a redução das chuvas, quando as médias climatológicas 
progressivamente decrescem, e a escassez de chuva é acentuada no mês de junho, quando é alcançada a média de $27,2 \mathrm{~mm}$.

Figura 2 - Comportamento sazonal de precipitação em Altamira (1975-2017)

Comportamento sazonal precipitação

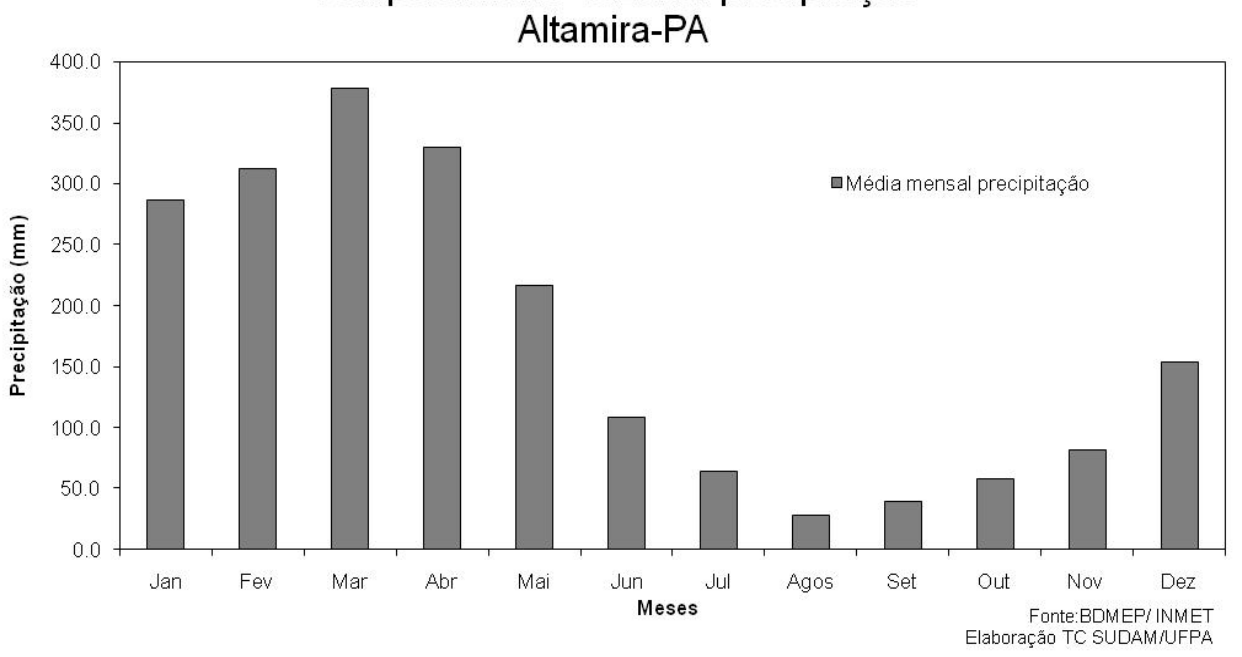

Fonte: BDMEP/INMET (2019).

Segundo relatos do representante do Sistema de Monitoramento e Alerta Hidroclimático UFPA/SUDAM, o primeiro boletim hidroclimático foi emitido para a cidade de Marabá, devido ao histórico de inundações no município. Na mesma época, também foi calibrado um modelo de previsão hidrológica, onde é possível prever o comportamento do rio com até 4 dias de antecedência. O mesmo modelo foi replicado posteriormente aos municípios de Altamira, Óbidos, Santarém, Oriximiná, entre outros.

Nos boletins hidroclimáticos emitidos para o município de Altamira, constam informações de precipitação observada, previsão de precipitação semanal e monitoramento e previsão do nível do rio Xingu.

Todos os boletins hidroclimáticos elaborados para Altamira podem ser encontrados no endereço eletrônico "defesacivil.sudam.gov.br", onde constam os boletins diários, mensais e sazonais. Além dos boletins, no site também podem ser encontradas informações sobre defesa civil, planos de contingências, ações preventivas aos desastres naturais e orientações e dicas à população de como proceder em situações de risco.

O boletim hidroclimático elaborado pela UFPA/SUDAM para o município de 
Altamira se constitui numa importante ferramenta de tomada de decisão para as autoridades da defesa civil local, quanto às ações de preparação e respostas a serem adotadas, por ocasião da ocorrência de desastres, possibilitando assim a mitigação dos danos materiais, sociais, econômicos e ambientais e principalmente a perda de vidas humanas (SUDAM, 2015).

A emissão de boletins pela UFPA/SUDAM era realizada durante todos os dias do ano, mesmo no período menos chuvoso. Entretanto, em outubro de 2018, os recursos destinados ao sistema foram suspensos e os boletins pararam de ser emitidos. Segundo relato do representante do sistema, foram solicitados novos recursos para que o mesmo volte a funcionar, pois sua operação carece de uma equipe multidisciplinar qualificada para transformar os dados brutos coletados em informação para a defesa civil e a população.

\section{Sistema de alerta hidrológico - CPRM}

O Sistema de Alerta de Eventos Críticos (SACE) foi desenvolvido pelo Serviço Geológico do Brasil (CPRM) e consiste em um sistema computacional feito em Java, que é capaz de coletar, armazenar, analisar e divulgar os dados das estações hidrometeorológicas instaladas. Este sistema disponibiliza os dados monitorados no site da CPRM, em forma tabular e gráfica, sendo permitida a consulta por qualquer pessoa interessada que tenha acesso à internet (CPRM, 2018).

Em 2014, a CPRM deu início ao estudo de viabilidade para implantação do Sistema de Alerta Hidrológico da Bacia do Rio Xingu (SAH Xingu). O sistema tem o objetivo de gerenciar e/ou reduzir os impactos causados por desastres hidrológicos (alagamentos, inundações e enxurradas), através do monitoramento contínuo, previsão dos níveis dos rios e divulgação de boletins.

Tais boletins são encaminhados diretamente para o Centro Nacional de Monitoramento e Alertas de Desastres Naturais (CEMADEN) e para a Defesa Civil (estadual e municipal), com o objetivo de alertar com a maior antecedência possível os agentes que irão executar as ações emergenciais e imediatas.

Além disso, os boletins hidrológicos também são divulgados no endereço eletrônico da CPRM para acesso público. De acordo com relato do representante do SAH Xingu, o público alvo do sistema são as agências governamentais, as instituições 


\section{RVISTA

públicas e privadas, a defesa civil e os cidadãos em geral.

Os dados hidrológicos que são utilizados para a produção dos boletins são provenientes da Rede Hidrometeorológica Nacional, de responsabilidade da Agência Nacional das Águas (ANA) e operada pela CPRM e demais parceiros. O SAH Xingu atende 5 municípios e uma população afetada direta ou indiretamente de aproximadamente 274.000 habitantes, sendo Altamira um dos municípios beneficiados do sistema (CPRM, 2018). Na Figura 3, observa-se a rede de estações hidrometeorológicas monitoradas na bacia do rio Xingu pela CPRM.

Figura 3 - Rede de estações hidrometeorológicas monitoradas na bacia do rio Xingu

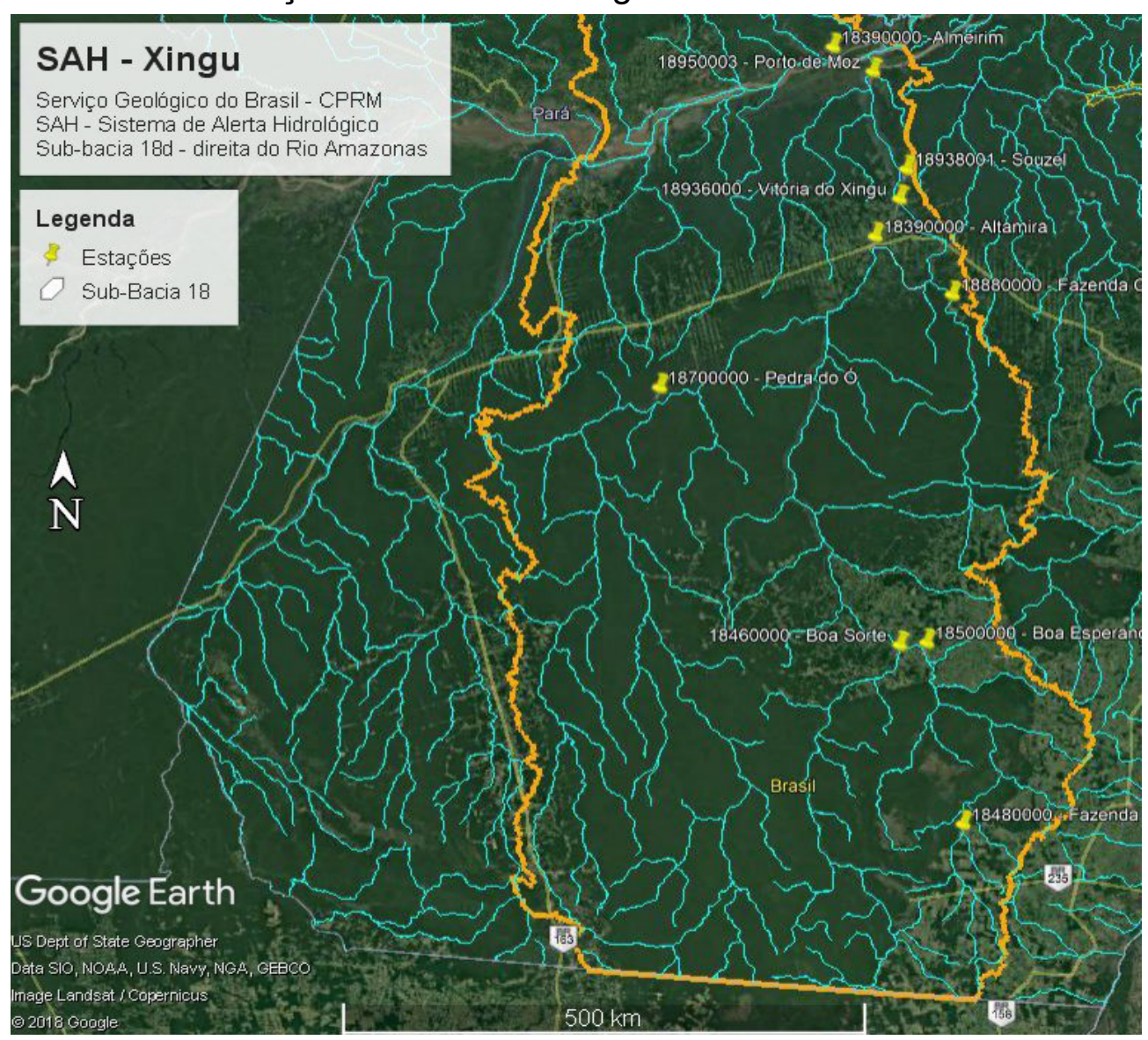

Fonte: CPRM (2018).

Nos boletins hidrológicos produzidos pela CPRM para o SAH Xingu, é possível extrair informações referentes aos níveis dos rios e se o nível está abaixo ou acima das cotas de atenção, de alerta ou de inundação. A CPRM definiu as seguintes cotas 
para o Rio Xingu na região de Altamira: 8,5 metros para a cota de atenção; 9 metros para a cota de alerta; e 9,5 metros para a cota de inundação. Na Figura 4, observa-se um gráfico do nível do Rio Xingu extraído de um boletim hidrológico emitido no dia 17 abril de 2018.

Figura 4 - Gráfico do Nível do Rio Xingu, 17/04/2018

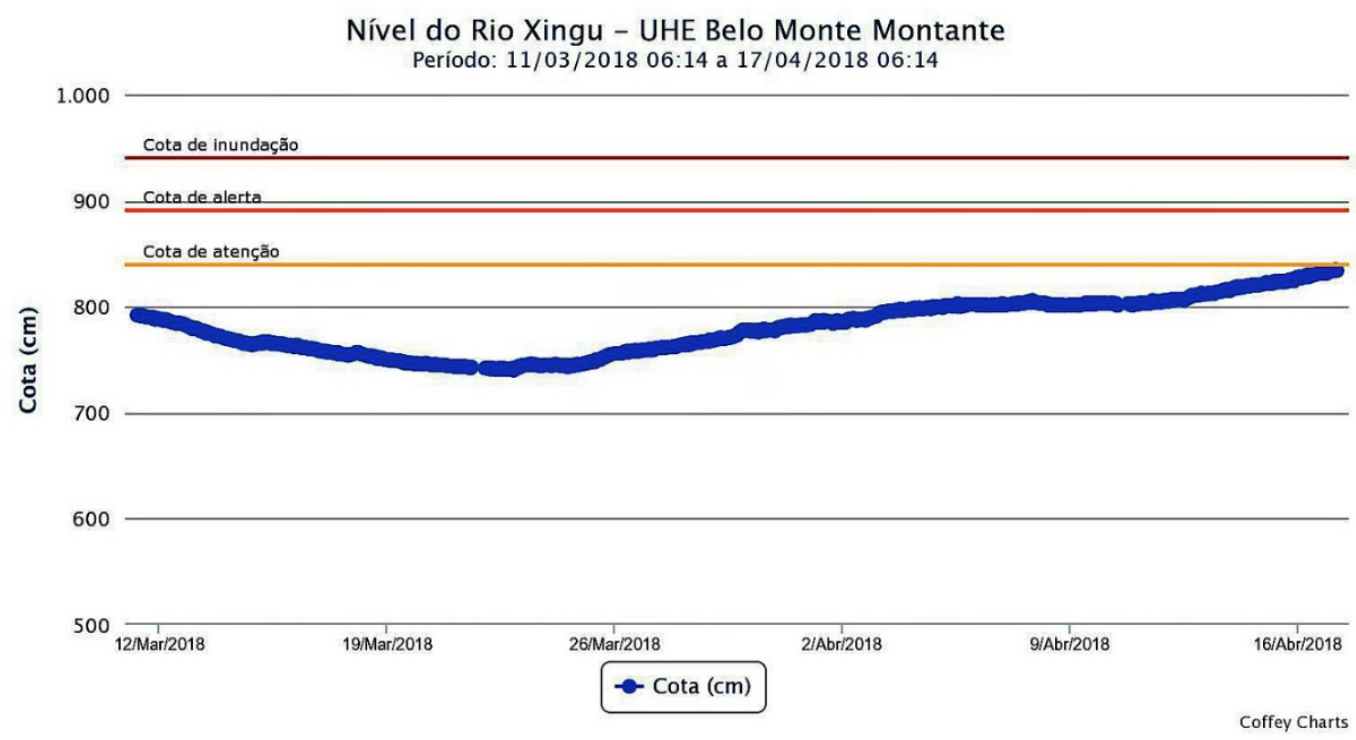

Fonte: CPRM (2018).

Nos boletins, também são realizadas estimativas e previsões para os próximos dias, permitindo que a Defesa Civil possa tomar decisões sobre políticas e ações para mitigar os riscos de inundações e secas com certa antecedência.

De acordo com relato do representante do SAH Xingu, a CPRM possui um modelo de previsão hidrológica de até 7 dias de previsão, com margem de erro de 15 centímetros para o nível d'água. Entretanto, é necessário que todas as estações estejam em funcionamento para que a previsão seja realizada.

$\mathrm{Na}$ última vistoria de campo realizada, foi elaborado um relatório sobre a situação de 6 estações hidrometeorológicas do SAH Xingu. Dessas 6 estações que foram analisadas, somente 2 (duas) estão em perfeito funcionamento, enquanto as outras precisam ser consertadas ou substituídas, o que compromete a previsão hidrológica do sistema.

É importante ressaltar que o monitoramento da CPRM é realizado durante todo o ano, mas os boletins hidrológicos são produzidos somente no período chuvoso, 
de janeiro a abril, considerado pela entidade como o período mais crítico e de monitoramento prioritário em comparação aos outros meses do ano.

\section{PERCEPÇÕES DOS AGENTES ENVOLVIDOS}

As percepções dos agentes envolvidos foram coletadas através de entrevistas semiestruturadas realizadas com 3 agentes: um representante do Sistema de Monitoramento e Alerta Hidroclimático UFPA/SUDAM, um representante do Sistema de Alerta Hidrológico CPRM e um representante da Defesa Civil de Altamira.

\section{Representante do Sistema de Monitoramento e Alerta Hidroclimático UFPA/ SUDAM}

A entrevista com o representante do Sistema de Monitoramento e Alerta Hidroclimático UFPA/SUDAM foi realizada no dia 9 de janeiro de 2019, às 10:30h, na sede administrativa da SUDAM, localizada na Travessa Antônio Baena, $\mathrm{n}^{\circ} 1113$, bairro do Marco, na cidade de Belém. Na entrevista, foram questionadas quais eram as dificuldades existentes no monitoramento e emissão de alertas.

O entrevistado julgou a extensão territorial do município e o número reduzido de estações como as principais dificuldades do monitoramento. Segundo ele, além do município de Altamira possuir área considerável, o número de estações operantes ainda é baixo, o que dificulta a previsão hidroclimática e o acompanhamento da situação real da bacia.

O representante da UFPA/SUDAM também citou a falta de preparo dos prefeitos e gestores municipais como um impedimento ao bom funcionamento dos sistemas de monitoramento e alerta, pois geralmente não sabem como solicitar recursos para investir em medidas de prevenção ou elaboram projetos que não são aprovados por conterem uma série de erros técnicos.

O entrevistado também pontuou a importância da capacitação dos gestores, da integração com a Defesa Civil e da comunicação com a comunidade em geral, pois o sistema de alertas só tem êxito se as informações repassadas forem recebidas por gestores e agentes capacitados que irão implementar as ações de prevenção e/ou 
mitigação dos danos.

\section{Representante do Sistema de Alerta Hidrológico da CPRM}

A entrevista com o representante do Sistema de Alerta Hidrológico da CPRM foi realizada no dia 21 de janeiro de 2019, às 15:30h, na sede administrativa da CPRM, localizada na Avenida Perimetral, n 3645, bairro do Marco, na cidade de Belém.

De acordo com o entrevistado, uma das maiores dificuldades do monitoramento na região do Xingu é a dificuldade do acesso às estações em casos de vistoria, considerando que as vias são precárias e que as equipes precisam percorrer boa parte do percurso por transporte aquático, geralmente em pequenas embarcações conhecidas popularmente como "voadeiras".

Outra dificuldade mencionada na entrevista foi a impossibilidade de vigilância em alguns dos locais de monitoramento. Grande parte das estações do SAH Xingu foram instaladas em propriedades privadas (fazendas, por exemplo) para evitar ao máximo que as mesmas sejam roubadas. Ainda assim, ocorrem casos de furto de estações por garimpeiros, que têm interesse nos painéis solares instalados nos aparelhos que emitem os dados via satélite.

De acordo com o entrevistado, se pelo menos uma estação parar de transmitir dados, seja porque foi furtada ou por defeito em alguma peça, o sistema já fica comprometido, pois o modelo de previsão hidrológica não poderá ser aplicado. $\mathrm{Na}$ primeira quinzena de fevereiro de 2019, uma equipe técnica realizará vistoria de campo em algumas estações que compõem a Rede de Estações Hidrometeorológicas do Xingu, com o objetivo de substituir as estações que foram furtadas ou que estão danificadas e sem funcionamento.

De acordo com o representante do SAHXingu, para solicitar novos equipamentos ou novas estações, é necessário fazer um pedido para a central da CPRM no Rio de Janeiro, que é responsável por receber os pedidos e encaminhar os materiais solicitados, mas que isso leva um certo tempo e que há casos em que o equipamento recebido não é compatível com o solicitado, atrasando o processo de substituição e/ ou conserto das estações e prejudicando o monitoramento e a previsão hidrológica.

O entrevistado ainda afirmou que a Prefeitura de Altamira não oferece nenhum suporte para a CPRM em casos de vistoria na região ou na implementação de programas de capacitação aos moradores, havendo contato da CPRM apenas com o 
Corpo de Bombeiros, que atua como Defesa Civil.

O representante da CPRM afirmou que na próxima visita à Altamira, marcada para a primeira quinzena de fevereiro de 2019 , irá buscar apoio junto à prefeitura para desenvolver ações em conjunto, que visem ensinar a população a acessar os boletins hidrológicos e como devem agir em casos de inundação. Segundo o entrevistado, a parceria da prefeitura e da defesa civil municipal nessa questão é indispensável, considerando a problemática recorrente de inundações no município.

\section{Representante da Defesa Civil de Altamira}

A entrevista com o representante da Defesa Civil de Altamira foi realizada no dia 03 de dezembro de 2018, às 15h, na Coordenadoria Estadual de Defesa Civil, localizada na Avenida Júlio César, n 3000, Bairro de Val-de-Cans, na cidade de Belém.

De acordo com o entrevistado, quem atua como Defesa Civil Municipal é o $9^{\circ}$ Grupamento Bombeiro Militar, sediado na Rua Abel Figueiredo, $n^{\circ} 733$, Bairro de Aparecida, no município de Altamira. A equipe de agentes da defesa civil, além de ser pequena, é a mesma que atua como bombeiro, o que faz com que os agentes não consigam desenvolver uma política efetiva e própria para defesa civil, diferente do município de Belém, que possui uma equipe de defesa civil específica, composta de meteorologistas, geógrafos e demais profissionais capacitados.

O representante da Defesa Civil Municipal declarou que o recebimento dos boletins hidrológicos, tanto por parte da UFPA/SUDAM quanto por parte da CPRM, é de extrema relevância para a adoção de medidas assistenciais em tempo hábil, mas que dependendo da magnitude do evento, necessitam do Estado.

O entrevistado mencionou como exemplo a inundação brusca que afetou o município de Altamira em abril de 2009, pontuando que neste evento, receberam apoio do quartel de Marabá, do comandante operacional da Defesa Civil Estadual, da Secretaria de Assistência Social do Estado, entre outros, que somaram esforços para controlar a situação com a maior urgência possível.

Porém, o entrevistado lamentou que este apoio se deu durante o desastre, quando o ideal seria que o poder público investisse na implementação de programas de prevenção e capacitação da população em casos de risco.

O representante da Defesa Civil Municipal ainda comentou sobre o que ele considera como "política da cheia", que seriam os benefícios que os moradores das 
áreas de risco teriam acesso durante e após as inundações. Segundo o entrevistado, muitas pessoas que não residem em áreas de risco, mas que possuem familiares ou amigos que residem, se direcionam a estas áreas no período chuvoso somente para se beneficiar de cestas básicas, suprimentos e até mesmo indenizações.

O entrevistado afirmou que o Corpo de Bombeiros de Altamira busca realizar palestras em escolas e oferecer capacitação aos moradores de áreas de risco sempre que possível, mas reconhece que mesmo com o histórico de inundações em Altamira, ainda há descaso na adoção de medidas preventivas por parte do município.

Também foi mencionado o fato de que muitos moradores não abandonam suas casas mesmo em períodos de cheia do rio, com receio de furto dos seus bens materiais, como móveis e eletrodomésticos, o que aumenta o risco à saúde humana e dificulta as ações de remanejamento para os abrigos.

Quando questionado sobre as medidas tomadas em casos de inundação, o entrevistado informou que após receber o alerta de risco, a defesa civil municipal aciona inicialmente a Secretaria de Meio Ambiente de Altamira (SEMAT) e a Secretaria de Planejamento (SEPLAN), pois o município não possui uma coordenaria específica para atuar em situações de risco.

Se o risco for de maior magnitude, aciona-se a Defesa Civil Estadual e os agentes de defesa civil dos municípios vizinhos. Neste caso, a prestação de socorro não seria imediata, e quanto maior for o tempo de espera, maior poderá ser o potencial de desastre.

Por fim, o entrevistado reconheceu que ainda há muito a se avançar na questão da defesa civil municipal, mas que ele tem esperança que com a implementação da Lei $n^{\circ}$ 12.608, de 10 de abril de 2012, que institui a Política Nacional de Proteção e Defesa Civil, que abrange a prevenção, mitigação, preparação, resposta e recuperação voltadas à proteção e defesa civil (BRASIL, 2012), o poder público comece a atuar a problemática das inundações em Altamira seja atenuada gradativamente.

\section{CONSIDERAÇÕES FINAIS}

A temática abordada neste trabalho possui extrema relevância para a comunidade acadêmica e a sociedade civil, considerando que pouco se discute sobre tais questões em nossa região e que a implementação dos sistemas de prevenção e 
alerta em áreas que tem casos recorrentes de inundações, como é o caso do município de Altamira, é essencial no que diz respeito à segurança e bem estar daqueles que residem em áreas vulneráveis.

As inundações em Altamira causam diversos prejuízos à população, deixando famílias desalojadas e desabrigadas, afetando a economia, o comércio e o cotidiano destas pessoas. De acordo com o Centro Universitário de Estudos e Pesquisas sobre Desastres - CEPED (2013), do total de 143 municípios do Pará, 58 registraram oficialmente situação anormal por inundação gradual, ao menos uma vez, durante o período de 1991 a 2012. No município de Altamira, foram registradas cerca de 13 ocorrências de inundações extremas recorrentes neste período, sendo Altamira o segundo município que mais registrou tais ocorrências, perdendo apenas para o município de Marabá, com 17 registros de ocorrência (CEPED, 2013).

Além dos prejuízos financeiros, também devem ser consideradas as perdas imensuráveis, como os bens pessoais e de valor sentimental, e a perda de entes queridos, causando dor e tristeza nas famílias atingidas.

A implementação dos sistemas de monitoramento e alerta da UFPA/SUDAM e da CPRM no município de Altamira é de extrema valia no que diz respeito tanto ao fornecimento de informações para o poder público e a defesa civil local, quanto à divulgação dos boletins hidrológicos para a comunidade em geral.

Entretanto, foi possível identificar, através dos relatos dos entrevistados, uma série de dificuldades existentes no monitoramento e na emissão dos alertas para o município de Altamira, como: a extensão territorial do município; a falta de investimentos e recursos aplicados aos sistemas; a dificuldade em realizar a manutenção e a vigilância das estações; a falta de programas de prevenção e capacitação em casos de desastres hidrológicos, tanto para os agentes de defesa civil local quanto para a população.

Outra questão analisada foi a atuação do município mediante desastres hidrológicos iminentes, onde observou-se que o município ainda não possui uma equipe específica e capacitada para lidar com situações de risco, mesmo apresentando um longo histórico de inundações e perdas irreparáveis.

Através das entrevistas, também puderam ser identificadas as fragilidades dos sistemas e da inexpressiva atuação do município na adoção de medidas preventivas e mitigatórias, considerando que o município não atua de forma intensiva na prevenção 
e capacitação da população.

Recomenda-se que o poder público busque atuar de forma conjunta tanto com os órgãos públicos responsáveis pelos sistemas de monitoramento e alerta quanto com os agentes de defesa civil, além de estabelecer contato constante com a população, através de informativos em programas televisivos, em rádios comunitárias, nas associações de moradores, nas redes sociais, entre outros.

Também é necessário que se invista em programas de capacitação dos agentes de defesa civil e dos moradores da região para enfrentar situações de risco iminente, além de realizar um planejamento urbano e territorial mais efetivo, com programas de remanejamento e fiscalização constante nas áreas de risco.

Através do monitoramento, é possível emitir o alerta com a maior antecedência possível para as autoridades competentes, mas se não houver a capacitação dos moradores para situações de risco, o trabalho dos agentes de defesa civil se torna mais dificultoso. Além da capacitação, também poderiam ser instaladas sirenes em áreas suscetíveis às inundações, que alertariam a população sobre o risco e todos saberiam como agir, diminuindo consideravelmente os danos e perdas nas comunidades atingidas.

Aconselha-se também que em pesquisas futuras sobre esta temática, sejam consultados outros agentes que também estão envolvidos nesta problemática, como a população diretamente afetada, a prefeitura municipal, membros de entidades públicas e privadas, entre outros, visando a participação e envolvimento de todos na solução ou remediação do problema em questão.

\section{REFERÊNCIAS}

CENTRO UNIVERSITÁRIO DE ESTUDOS E PESQUISAS SOBRE DESASTRES (CEPED). Atlas brasileiro de desastres naturais - Volume Pará. Universidade Federal de Santa Catarina. 2. ed. rev. ampl. - Florianópolis: CEPED, UFSC, 2013.

FAVA, M. C.; MENDIONDO, E. M.; SOUZA, V. C. B.; ALBUQUERQUE, J. P.; UEYAMA, J. Proposta metodológica para previsões de enchentes com uso de sistemas colaborativos. XX Simpósio Brasileiro de Recursos Hídricos. 
Associação Brasileira de Recursos Hídricos (ABRH). Bento Gonçalves - RS, 2013.

INSTITUTO BRASILEIRO DE GEOGRAFIA E ESTATÍSTICA (IBGE). Panorama do Município de Altamira. Censo Demográfico, 2010. Disponível em: https://cidades. ibge.gov.br/brasil/pa/altamira/panorama. Acesso em 10 dez 2018.

INSTITUTO NACIONAL DE METEOROLOGIA (INMET). Gráficos de precipitação - Estações convencionais. Disponível em: http://www.inmet.gov.br/portal/index. php?r=home/page\&page=rede_estacoes_conv_graf. Acesso em: 02 jan 2019.

KRON, W. Correlation between convective heavy rainfalls and GPS Precipitable Water. In: International Workshop on GPS Meteorology: Groundbasedandspace borne applications, Tsukuba, Japão, 14-17/01/2003, Proceedings, MEXT-JISTEC.

MINISTÉRIO DO PLANEJAMENTO E ORÇAMENTO. Glossário de Defesa Civil - Estudos de riscos e medicina de desastres. Secretaria Especial de Políticas Regionais. Departamento de Defesa Civil. $2^{a}$ edição. Revista e ampliada. Brasília, 1998.

OLIVEIRA, R.; ROCHA, P.; BARBOSA, M. Historicidade das inundações para compreensão do efeito de retroalimentação positiva em bacias hidrográficas urbanas - estudo de caso em Altamira. Revista GeoAmazônia, Belém, v. 03, n.06, p. 01 - 13, jul./dez. 2015. ISSN: 2358-1778 (online) 1980-7759 (impresso).

PREFEITURA MUNICIPAL DE ALTAMIRA. Relatório do Plano Diretor - Volume II. Altamira, PA, 2010.

SAMUELS, P. G. An overview of flood estimation and flood prevention. In: TOESMANN, F. \& KOCH, M. (eds). River flood defense, Herkules Vg, Kassel, Alemanha, v. 2, pp. G1- G9 (Kassel Reports of Hydraulic Eng. No. 9/2000). 
SERVIÇO GEOLÓGICO DO BRASIL (CPRM). Ação Emergencial para Delimitação de Áreas em Alto e Muito Alto Risco a Enchentes e Movimentos de Massa. Campinas, São Paulo, 2013.

SERVIÇO GEOLÓGICO DO BRASIL (CPRM). Bacia do Rio Xingu Apresentação. Disponível em: http://www.cprm.gov.br/sace/index_bacias_ monitoradas.php\#. Acesso em: 10 nov 2018.

SOARES, A.; PEREIRA, B.; SANTOS, C.; RAMOS, C.; OLIVEIRA, P.;VAZ, T. Inundações urbanas: o caso das ruas de $\mathbf{S t}^{\mathrm{a}}$. Marta, S. José e Portas de $\mathbf{S t}^{\mathbf{o}}$ Antão (Lisboa). In: X Colóquio Ibérico de Geografia, Évora. Lisboa, 2005.

SUPERINTENDÊNCIA DE DESENVOLVIMENTO DA AMAZÔNIA (SUDAM). Monitoramento e previsão hidroclimatológica para alertas de desastres na Amazônia. Disponível em: http://www.sudam.gov.br/index.php/servidores/84cordec/206-4-4-monitoramento-e-previsao-hidroclimatologica-para-alertas-dedesastres-na-amazonia. 2015. Acesso em 10 jan 2019.

TUCCl, Carlos E.M. Gestão de Águas Pluviais Urbanas. Ministério das Cidades Global Water Partnership - World Bank - Unesco, 2005. 